\title{
Medical Treatment of Gallstones
}

\author{
G. D. BELL, MD, MSc, MRCP (UK) \\ Senior Lecturer, Department of Therapeutics, \\ City Hospital, Nottingham
}

Most gallstones formed by patients in westernised communities consist predominantly of crystalline cholesterol monohydrate (Sutor and Wooley, 1971). From the medical point of view this is just as well, since there is no drug that is effective in dissolving the less common types of gallstones such as pigment stones and those consisting of the calcium salts of phosphate, carbonate, and palmitate available at the moment (Sutor and Wooley, 1973).

Cholesterol is virtually insoluble in water (Bourges et al., 1967); the relatively large amount of cholesterol found in human bile is normally held in micellar solution by the combined detergent action of bile salts and phospholipid (Hofmann and Small, 1967). It is now generally felt that cholesterol cholelithiasis is primarily a disease of the liver rather than of the gallbladder because the patient's bile is already 'lithogenic' before it reaches the gallbladder (Small and Rapo, 1970). Figure 1 summarises some of the mechanisms thought to be of importance in the pathogenesis of cholesterol gallstones. We know that much of the cholesterol and all the bile salts in bile are synthesised by the hepatic microsomes. The rate-limiting enzyme for the synthesis of cholesterol from acetate is 3-hydroxy-3 methyl glutaryl coenzyme A reductase (HMGCoAR), while that controlling the synthesis of cholic and chenodeoxycholic acid, the two primary bile acids in man, is cholesterol $7 \alpha$ hydroxylase $(7 \alpha \mathrm{OH})$. Liver biopsy material taken from patients with cholesterol gallstones has shown that the activity of HMGCoAR is abnormally high, while that of $7 \alpha \mathrm{OH}$ tends to be low (Coyne et al., 1976) when compared with control subjects. These abnormalities may explain why some patients with cholelithiasis have an absolute increase in their 24-hour output of biliary cholesterol (Grundy et al., 1972), and a decrease in bile acid pool size (Vlahcevic et al., 1970). Thus, the combination of too much cholesterol and too little detergent bile salts in bile renders the mixed micelles supersaturated or lithogenic, and so the stage is set for the appearance of microcrystals of cholesterol in bile and their growth into macroscopic stones.

It is now six years since the first reports of gallstone dissolution using the bile acid chenodeoxycholic acid (CDCA) (Danzinger et al., 1972; Bell et al., 1972). The postulated mode of action of CDCA is shown in Fig. 2. CDCA reduces biliary cholesterol output relative to bile salt secretion (Northfield et al., 1975) so that the bile to This article is based on a paper read at the College Regional Conference held at Nottingham in September 1978. which the patient's stones are exposed is less than saturated with cholesterol. The gallstones dissolve because they are constantly being bathed in bile, which has 'cholesterol holding capacity'. The reason that CDCA is an effective cholelitholytic agent probably relates to the fact that it depresses hepatic HMGCoAR activity (Coyne et al., 1976; Salen et al., 1973) whereas cholic acid (CA) does not.

It can also be seen from Fig. 2 that when CDCA, exogenous bile acid, is fed to patients the, endogenous synthesis of bile acids from cholesterol is reduced as a result of depression of microsomal $7 \alpha \mathrm{OH}$. It was postulated (Small, 1971) that this might result in hypercholesterolaemia, but fortunately this has not occurred (for references see Bell, 1978a).

In the bowel there are bacteria capable of $7 \alpha$ dehydroxylating CDCA ( $3 \alpha 7 \alpha$ dehydroxycholanoic acid) to lithocholic acid ( $3 \alpha$ monohydroxycholanoic acid). Although both CDCA and lithocholic acid are hepatotoxic in rabbits (Holsti, 1962) rats (Palmer, 1969), rhesus monkeys (Dyrszka et al., 1976), and baboons (Morrissey et al., 1975), fears of similar problems in man appear

Figure 1. Proposed biochemical abnormalities in the liver which lead to the secretion of bile that is supersaturated with cholesterol-see text. BAP=Bile acid pool, $C A=$ Cholic acid, $C D C A=$ Chenodeoxycholic acid.

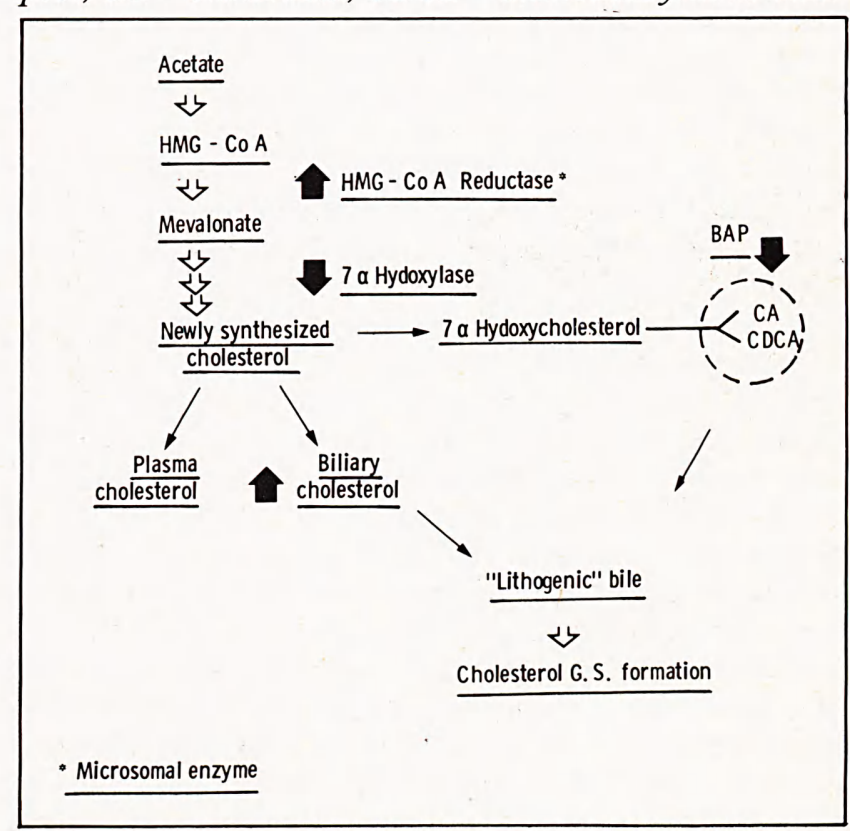




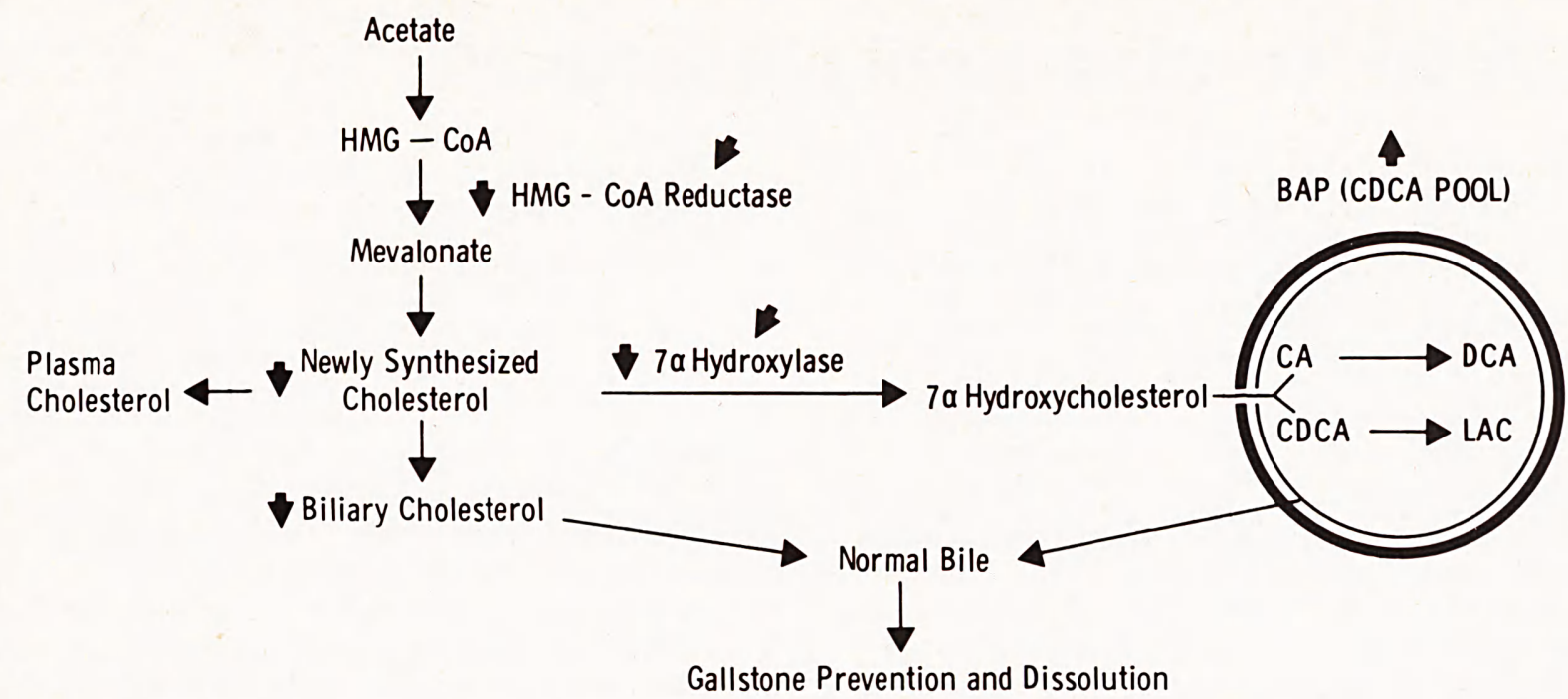

Figure 2. Proposed mechanism of action of chenodeoxycholic acid (CDCA)-see text.

unfounded (Bell et al., 1974; Bell, 1978a). Man possesses two biochemical mechanisms believed to minimise the toxicity of lithocholic acid. Salen et al. (1976) and Stiehl et al. (1975) reported increased levels of ursodeoxycholic acid averaging 17 per cent of the total bile acids in patients treated with CDCA. Ursodeoxycholic acid is the $7 \beta$ hydroxy epimer of CDCA ( $3 \alpha 7 \beta$ dihydroxycholanoic acid), and is normally found only in trace amounts in human bile. The other, perhaps most important, mechanism for reducing the toxicity of biliary lithocholate is the enhanced sulphation by the human liver (Palmer, 1967; Cowen et al., 1975). Sulphated lithocholate does not appear to be toxic to laboratory animals (Czyban and Stiehl, 1975) and, because of its polarity, is only poorly re-absorbed back into the enterohepatic circulation (Cowen et al., 1975).

CDCA was released on to the market in the UK in 1978 under the trade name of Chendol (Weddell Pharmaceuticals Ltd). As the manufacturers rightly stressed, this drug is only of use if the patient's gallbladder is radiologically opacifying. Obviously, if the cystic duct is blocked, the desaturated bile produced in the liver cannot get into the gallbladder to promote stone dissolution. They also rightly stress that stones coated with a protective rim of calcium salts, i.e. are radioopaque, do not respond to CDCA. What is, I think, a little misleading is the 93 per cent success rate claimed for patients with radiotranslucent stones and a functioning gallbladder treated with CDCA for one year. The reference quoted in their advertising literature to support these figures is, in fact, an abstract (Maton et al., 1977a) of a paper read at a British Society of Gastroenterology meeting, at which meeting Dr Maton stressed that this group of patients were highly selected. Patients who were obese, had stones in excess of $1.5 \mathrm{~cm}$ diameter, and did not show an improvement in the cholesterol solubilising capacity of their bile on repeat duodenal intubation were automatically excluded. On the other hand, the very low success rate for CDCA reported by Professor Bouchier's group (Bateson et al., 1978) perhaps fails to do the drug justice, since the dose employed in many of the patients was less than the $15 \mathrm{mg} / \mathrm{kg}$ body weight per day thought to be necessary to obtain optimal results (Iser et al., 1975).

'Chenotherapy' has been well reviewed by Dowling (1977) and a comprehensive list of relevant references published by Hofmann (1977). It appears to be a safe treatment (Bell, 1978a) and will undoubtedly prove of use in a selected group of patients who have small radiotranslucent stones, minimal symptoms and some medical, surgical or psychological contra-indication to cholecystectomy. Its main disadvantage is that treatment is very slow; a patient with a solitary cholesterol stone of more than $1 \mathrm{~cm}$ diameter can expect to wait at least a year before any evidence of dissolution can be seen radiologically, and possibly for three or more years before dissolution is complete (Dowling, 1977).

The Japanese have used ursodeoxycholic acid (UDCA) (originally derived from the Japanese white-collared bear) for many years as a choleretic. Recently, they have reported successful dissolution of cholesterol gallstones using this bile acid (Nakagawa et al., 1977). Professor Dowling's group at Guy's Hospital has confirmed this finding, and shown that UDCA is as effective as CDCA in half to two-thirds of the dose, and works by inhibiting hepatic HMGCoAR levels (Maton et al., 1977b). The other advantages of UDCA over CDCA are that it does not cause diarrhoea, and does not produce hypertransaminasaemia (Nakagawa et al., 1977; Maton et al., $1977 \mathrm{~b})$. It has yet to be shown that patients' gallstones dissolve more quickly with UDCA than with CDCA. The two main disadvantages of UDCA, as far as the UK is concerned, are that UDCA is synthesised from CDCA and so is liable to be prohibitively expensive, and it is likely to be several years before it gets through the Committee on Safety of Medicines to become generally available on prescription. This interesting compound is thus likely to remain primarily a research tool for some years to come.

There is, however, another drug, not a bile acid, that is freely available on prescription in the UK, which I feel 
Table 1. Chemical composition of Rowachol-each entericcoated capsule contains $0.1 \mathrm{~g}$ of above liquid.

\begin{tabular}{|c|c|c|}
\hline Drug substance & $\begin{array}{l}\text { Trivial } \\
\text { name }\end{array}$ & $\begin{array}{c}\text { Composition } \\
(\%)\end{array}$ \\
\hline $\begin{array}{l}\text { 1-methyl-4-isopropyl- } \\
\text { cyclohexanol-(3) }\end{array}$ & Menthol & 32 \\
\hline $\begin{array}{l}\text { 1-methyl-4-isopropyl- } \\
\text { cyclohexanone-(3) }\end{array}$ & Menthone & 6 \\
\hline $\begin{array}{l}2,6,6,- \text { trimethyl-bicyclo-(3.1.1.)- } \\
\text { heptene-(2) }\end{array}$ & Pinene & 17 \\
\hline $\begin{array}{l}\text { 1,7,7-trimethyl-bicyclo-(2.2.1)- } \\
\text { heptanol-(2) }\end{array}$ & Borneol & 5 \\
\hline $\begin{array}{l}\text { 2,2-dimethyl-3-methylene-bicyclo- } \\
\text { (2.2.1)-heptane }\end{array}$ & Camphene & 5 \\
\hline 1,8-oxido-p-menthane & Cineol & 2 \\
\hline Olive oil & - & 33 \\
\hline
\end{tabular}

merits more detailed consideration as a possible cholelitholytic agent to be used either alone, or possibly as an adjuvant to CDCA therapy. Rowachol (Rowa Ltd, Bantry, Co. Cork, Republic of Ireland) is a proprietary essential oil preparation that contains 6 cyclical plant monoterpenes. The exact composition is shown in Table l. In the rat, this compound significantly lowered hepatic HMGCoAR levels (Fig. 3) (Bell et al., 1978b),
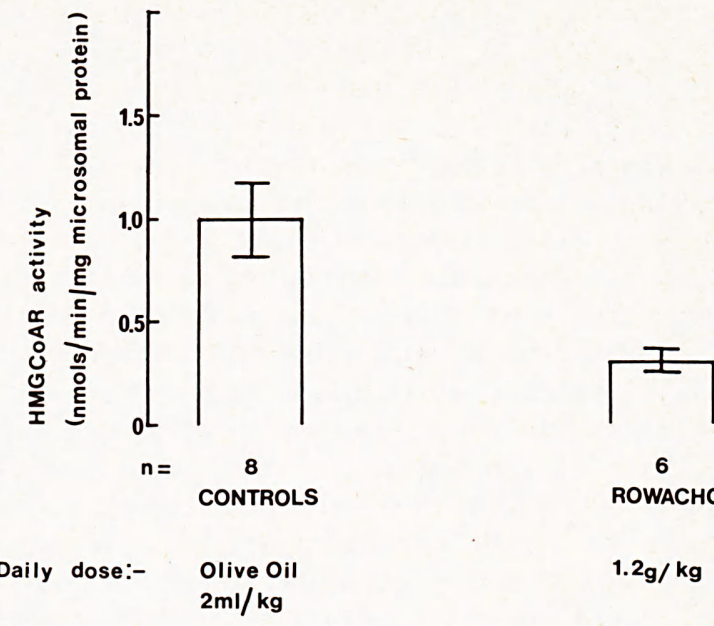

6

ROWACHOL

$1.2 \mathrm{~g} / \mathrm{kg}$

Figure 3. Effect of the proprietary essential oil preparation Rowachol on hepatic HMGCoAR levels in the rat (animals in both control and treated groups night/day adapted and killed at mid point of dark cycle when HMGCoAR levels known to be maximal, last dose of either olive oil or Rowachol liquid given 17 hours prior to death).

Figure 4. Oral cholecystogram of male patient V.W. aged 62 shows (left) four large (greater than $1.5 \mathrm{~cm}$ diameter) and multiple small radiolucent gallstones totally filling the gallbladder. He was started on Rowachol (2 capsules t.d.s.) in August 1977 and the cholecystogram repeated after just over six months' treatment. The second radiograph (right), slightly obscured by gas shadows, showed that the four largest stones were diminished in size while the remaining smaller stones had completely disappeared.

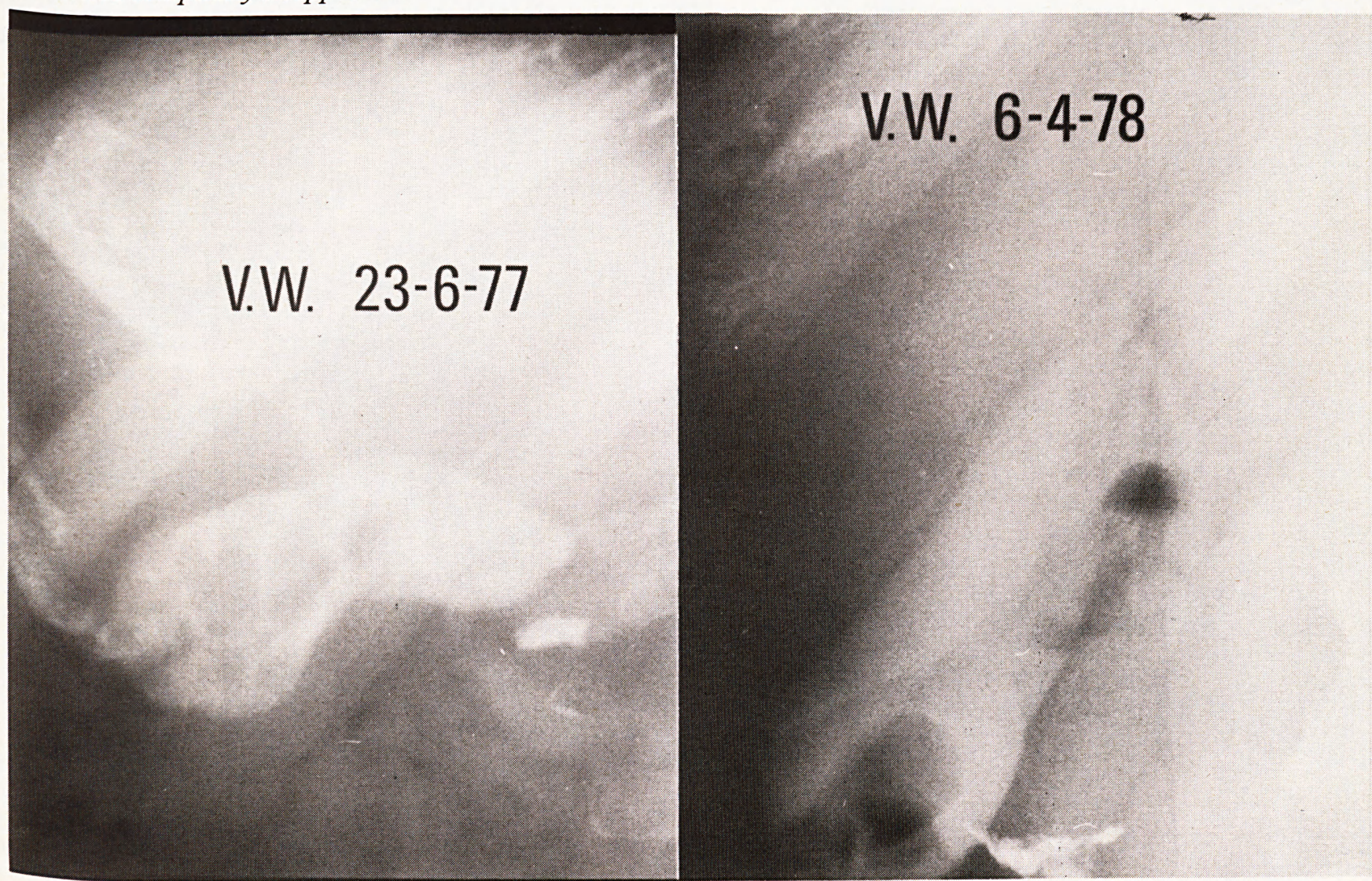


and in man it enhanced the cholesterol solubility of patients' bile (Doran et al., 1977). We have now treated a total of 24 patients with Rowachol in a dose of one capsule per $10 \mathrm{~kg}$ body weight per day for periods of six months or more. The drug was well tolerated and no evidence of hepatotoxicity was observed. Seven of the 24 patients have so far shown evidence of stone dissolution/ disappearance - an example is shown in Fig. 4. Four of the seven successes with Rowachol occurred in patients with common duct stones. This is in itself of some interest, since Bateson et al. (1978) found that only one out of 10 patients with similar stones responded to CDCA. Five of the remaining nine had to be operated on because of the development of obstructive jaundice. Figure 5 shows the operative cholangiogram and postoperative $\mathrm{T}$-tube cholangiogram of a 42 -year-old woman. Since several of her stones were high up in the left and right hepatic ducts, hence relatively inaccessible, the $\mathrm{T}$-tube was removed and she was treated with Rowachol. Figure 6 shows serial IVCs after 3 and 9 months' treatment. She remains well and her liver function tests are within normal limits.

Rowachol is not a new drug; it has, in fact, been extensively used on the continent of Europe for over 25 years. It is mainly prescribed for its choleretic and spasmolytic properties rather than as a cholelitholytic agent. There have, however, been a number of reports in the German (Greif and Michl, 1957; Sarreither, 1955),
Japanese (Kameda, 1960; Okabe, 1960; Noda et al., 1965) and English (Hordinsky, 1971, 1973) literature of patients' gallstones dissolving as a consequence of prolonged courses of Rowachol. Taking our own figures and those of the papers quoted above (see Table 2), a total of 286 patients with radiologically proven gallstones were observed for a total of 174.1 patient years. In this time 29 patients' stones disappeared or showed evidence of dissolution. To study the spontaneous rate of gallstone dissolution/disappearance Wolpers (1972) followed up 270 patients from 1949 to 1972 . The average follow-up time was seven years, which means $270 \times 7=1,890$ patient-years of observation. In this time Wolpers observed eight patients' gallstones to dissolve/disappear spontaneously. When the 286 Rowachol treated patients detailed in Table 2 are compared with Wolpers' 270 untreated patients, the differences in gallstone dissolution/disappearance rate is highly significant $(\mathrm{p}<0.002)$.

The fact that Rowachol contains no less than six terpenes may at first seem illogical. The manufacturers found that this mixture gave, in bile fistula rats, a larger and more sustained choleresis than any of its individual constituent terpenes in equimolar amounts. These results have been confirmed by Mörsdorf (1965). Dr Aliya Middleton and her colleagues in the University Department of Biochemistry at Nottingham are currently doing similar experiments in the rat to see whether all or only

Figure 5. Shows both the operative cholangiogram (left) and postoperative T-tube cholangiogram (right) of a 42-yearold woman, E.C., with gallstones. Many of the retained stones were surgically inaccessible high up in the left and right hepatic ducts. (See also Figure 6.)

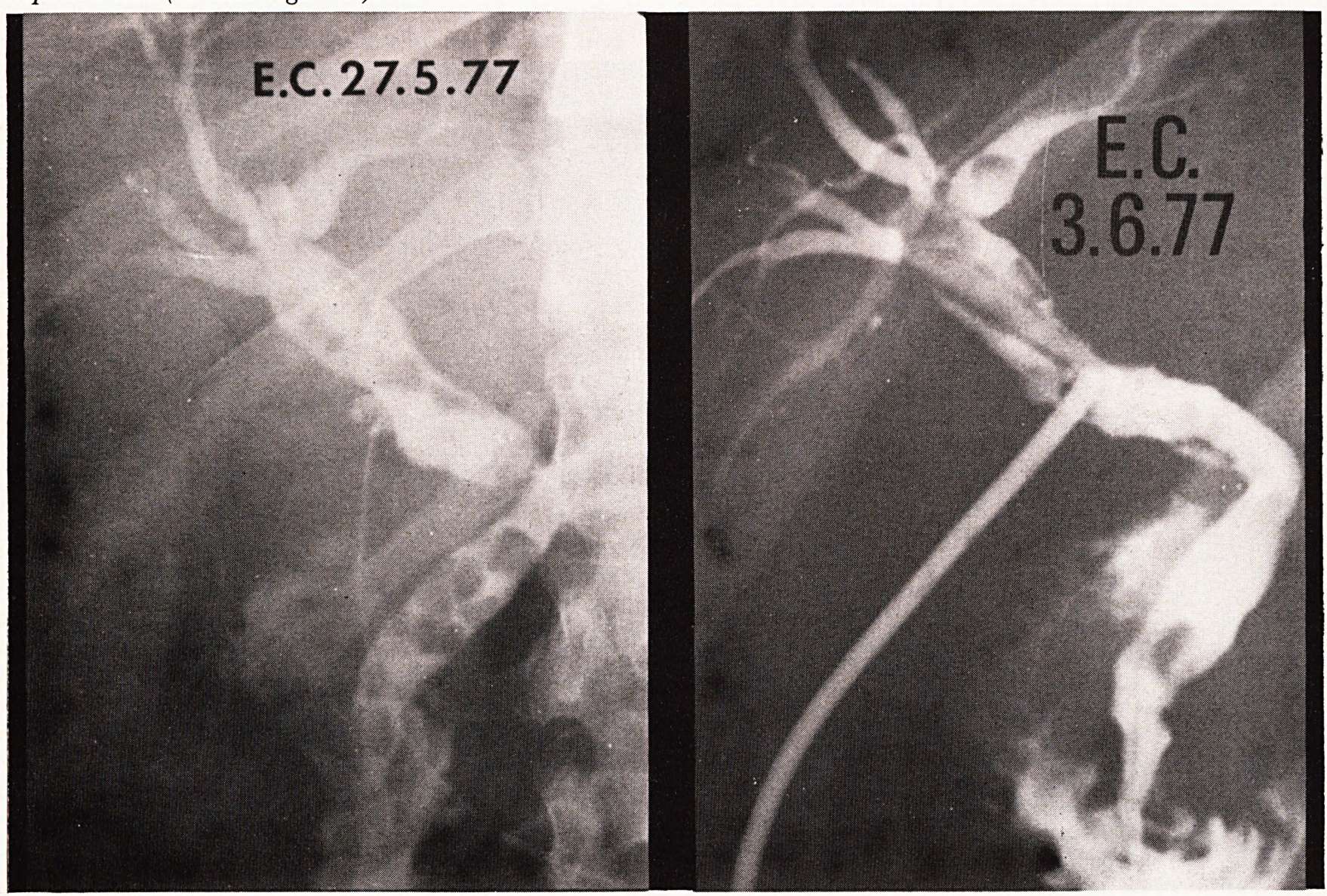




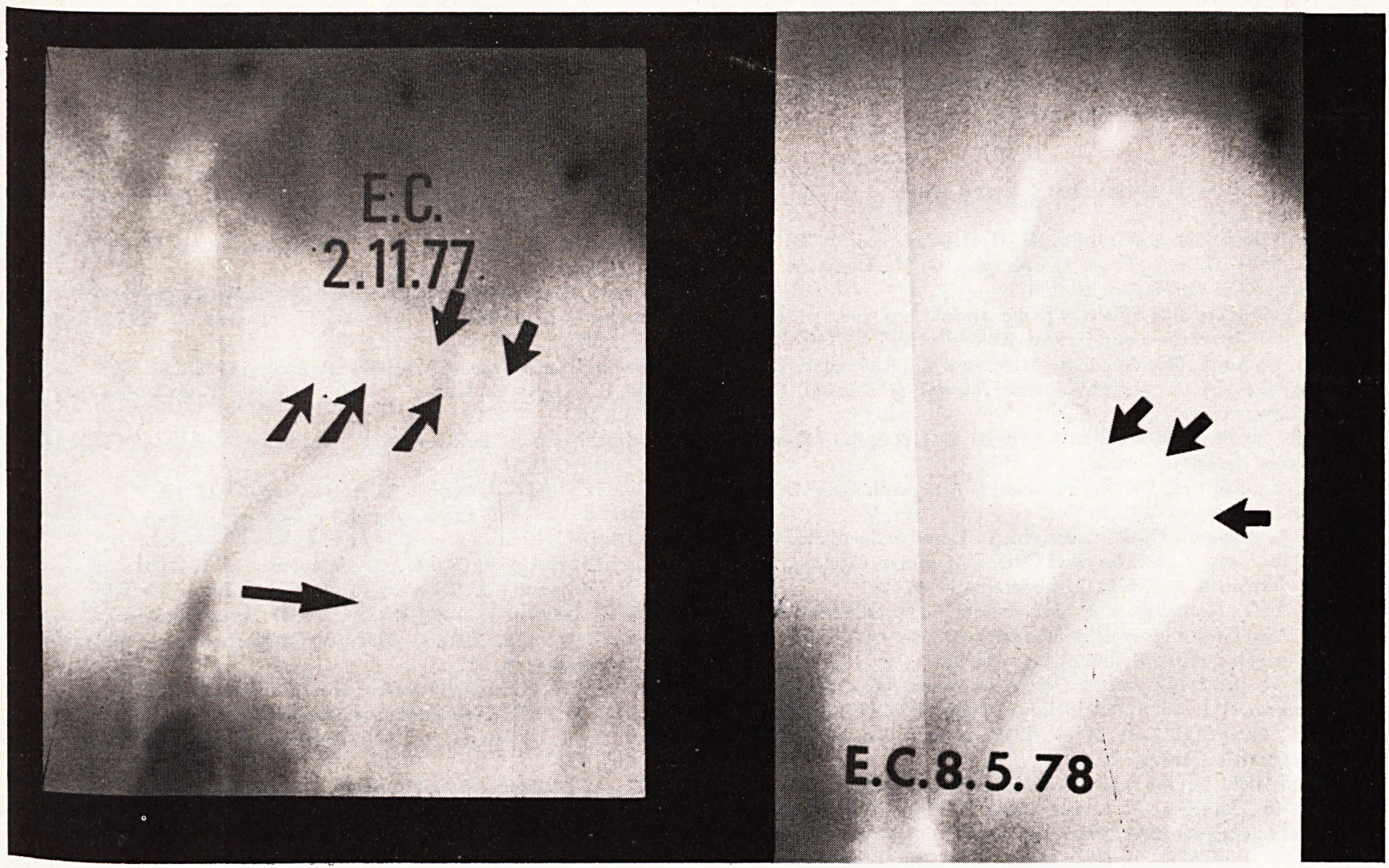

Figure 6. Showing follow-up intravenous cholangiograms done on the same patient as Figure 5 after five months (left) and 11 months (right) of treatment with Rowachol (2 capsules t.d.s.). The most recent examination shows only three stones (arrowed) remaining in the common bile duct.

some of the individual terpenes in Rowachol depress hepatic HMGCoAR levels, and are therefore of importance from the cholelitholytic as opposed to choleretic point of view.

Menthol, the major terpene constituent of Rowachol, is mainly metabolised by the liver to menthol glucuronide and then excreted in the urine and bile. Menthol glucuronide is known to enhance the solubility of both calcium carbonate and calcium phosphate in aqueous solutions (Neuberg and Grauer, 1951). It is possible, therefore, that this is the mechanism to explain the empirical observation that occasionally even radioopaque gallstones have been observed to get smaller and finally dissolve as a result of prolonged terpene therapy (Weithaler, 1959; Hordinsky, 1971).

\section{Conclusion}

CDCA has recently been released on to the market in the UK. It appears safe and is reasonably effective in nonobese subjects with functioning gallbladders and small non-opaque gallstones ( $<1 \mathrm{~cm}$ diameter). A patient with large stones $(>1 \mathrm{~cm}$ diameter $)$, particularly if obese, may require several years of CDCA therapy to ensure success. There is therefore a need to develop more effective drugs and/or agents that can be used in combination with CDCA. Recent reports that UDCA also dissolves gallstones are of considerable interest. UDCA is more expensive than CDCA and is unlikely to become freely available for some years. The proprietary essential oil preparation Rowachol is safe, virtually without adverse

Table 2. Published figures for gallstone dissolution/disappearance using Rowachol.

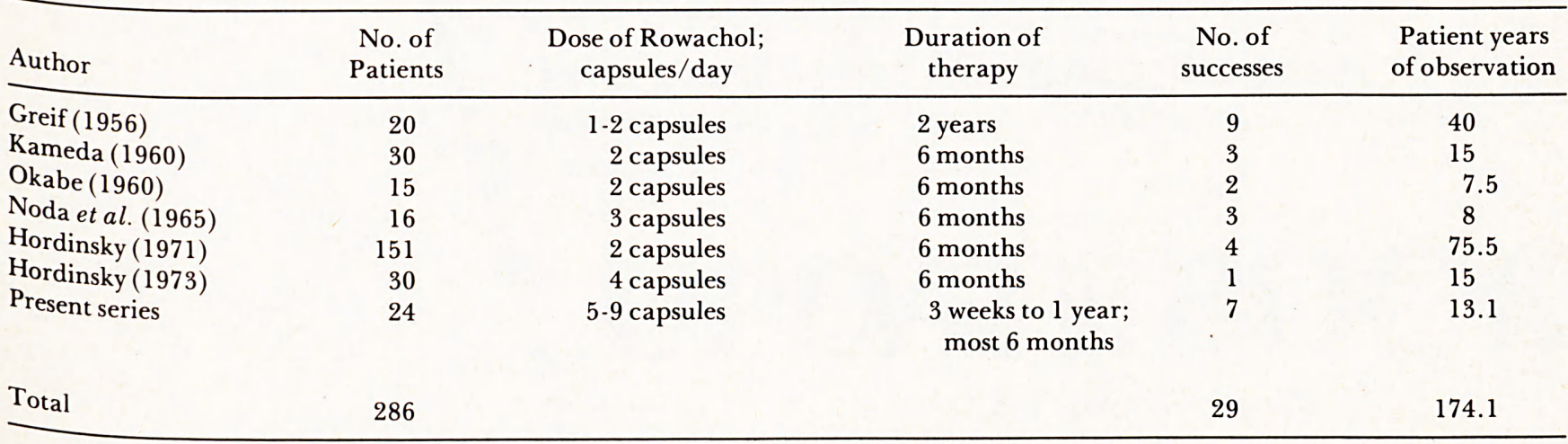


effect, and is a fraction of the cost of CDCA. This 'essential oil' formulation and its individual constituent cyclical plant terpenes merit further investigation as possible gallstone dissolving agents.

\section{References}

Bateson, M. C., Ross, P. E., Murison, J. and Bouchier, I. A. D. (1978) Lancet, 1, 1111.

Bell, G. D., Whitney, B. and Dowling, R. H. (1972) Lancet, $2,1213$.

Bell, G. D., Mok, H. Y. I., Thwe, M., Murphy, G. M., Henry, K. and Dowling, R. H. (1974) Gut, 15, 165.

Bell, G. D. (1978a) In Side Effects of Drugs Annual 2, p. 299. (ed M. N. G. Dukes). Amsterdam and Oxford: Excerpta Medica.

Bell, G. D., Doran, J., Middleton, A., Middleton, B., Richmond, C. R. and White, D. A. (1978b) British Journal of Clinical Pharmacology, in press.

Bourges, M., Small, D. M. and Dervichian, D. G. (1967) Biochimica et biophysica Acta (Amsterdam), 137, 157.

Cowen, A. E., Korman, M. G., Hoffmann, A. F. and Cass, O. W. (1975) Gastroenterology, 69, 59.

Coyne, M. J., Bonorris, G. G., Goldstein, L. I. and Schoenfield, L. J. (1976) Journal of Laboratory and Clinical Medicine, 87, 281.

Czyban, P. and Stiehl, A. (1975) Gastroenterology, 4, 468.

Danzinger, R. G., Hofmann, A. F., Schoenfield, L. J. and Thistle, J. L. (1972) New England Journal of Medicine, 286, 1.

Doran, J., Keighley, M. R. B. and Bell, G. D. (1977) Gut, 18, A977.

Dowling, R. H. (1977) In Clinics in Gastroenterology, Bile Acids. (ed G. Paumgartner). London, Philadelphia, Toronto: W. B. Saunders.

Dyrszka, H., Salen, G., Zaki, F. G., Chen, T. and Mosbach, E. H. (1976) Gastroenterology, 70, 93.

Greif, S. and Michl, F. (1957) Der Praktische Arzt, 11, 866.

Grundy, S. M., Metzger, A. L. and Adler, K. D. (1972) Journal of Clinical Investigation, 51, 3026.

Hofmann, A. F. (1977) In Chenodeoxycholic Acid and Gallstone Dissolution. Baltimore: University Park Press. Lancaster: M.T.P. Press.

Hofmann, A. F. and Small, D. M. (1967) Annual Review of Medicine, 18, 333.

Holsti, P. (1962) Acta Pathologica et Microbiologica Scandinavica, 54, 479.
Hordinsky, B. Z. (1971) Minnesota Medicine, 54, 649.

Hordinsky, B. Z. (1973) Shevchenko Scientific Society, VIII, 1.

Iser, J. H., Dowling, R. H., Mok, H. Y. I. and Bell, G. D. (1975) New England Journal of Medicine, 293, 378.

Kameda, H. (1960) Naika (Japan), 6, 3.

Maton, P. N., Iser, J., Murphy, G. M. and Dowling, R. H. (1977a) Gut, 18, A976 (abstract).

Maton, P. N., Murphy, G. M. and Dowling, R. H. (1977b) Lancet, 2, 1277.

Morrissey, K. P., McSherry, C. K. and Swarm, R. L. (1975; Surgery, $77,851$.

Mörsdorf, K. (1965) Bulletin de Chimie Thérapeutique, p. 442.

Nakagawa, S., Makino, L., Ishizaki, T. and Dohi, L. (1977) Lancet, 2, 367.

Neuberg, C. and Grauer, A. (1951) Enzymologia, 15, 115.

Noda, E., Kuriyama, H. and Tokuda, A. (1965) Naika Hokan (Japan), $12,19$.

Northfield, T. C., La Russo, N. F., Hofmann, A. F. and Thistle, J. L. (1975) Gut, 16, 12.

Okabe, H. (1960) Shokakibyo No Rinsho (Japan), 12, 12.

Palmer, R. H. (1967) Proceedings of the National Academy of Sciences, $58,1047$.

Palmer, R. H. (1969) In Bile Salt Metabolism, p. 184. (ed L. Schiff, J. B. Carey and J. M. Dietschy.) Springfield, Illinois: Thomas.

Salen, G., Nicolau, G. and Shefer, S. (1973) Clinical Research, 21, 523.

Salen, G., Tint, G. S. and Eliav, B. (1976) Journal of Clinical Investigation, 53, 612 .

Sarreither, W. (1955) Medizinische Monatsschrift, 9, 97.

Small, D. M. (1971) New England Journal of Medicine, 284, 214.

Small, D. M. and Rapo, S. (1970) New England Journal of Medicine, 283, 53.

Stiehl, A., Raedsch, R. and Regula, M. (1975) Verhandlungen der Deutschen Gesellschaft für Innere Medizin, 2, 13.

Sutor, D. J. and Wooley, S. E. (1971) Gut, 12, 55.

Sutor, D. J. and Wooley, S. E. (1973) Gut, 14, 215.

Vlahcevic, Z. R., Bell, C. C., Buhac, I., Farrar, J. T. and Swell, L. (1970) Gastroenterology, 59, 165.

Weithaler, K. (1959) Medizinische Klinik, 54, 1645.

Wolpers, C. (1972) In Bile Acids in Human Diseases II, p. 171. (ed P. Back and W. Gerok.) Stuttgart and New York: F. K. Schattauer Verlag.

\section{INDEX TO ADVERTISERS}

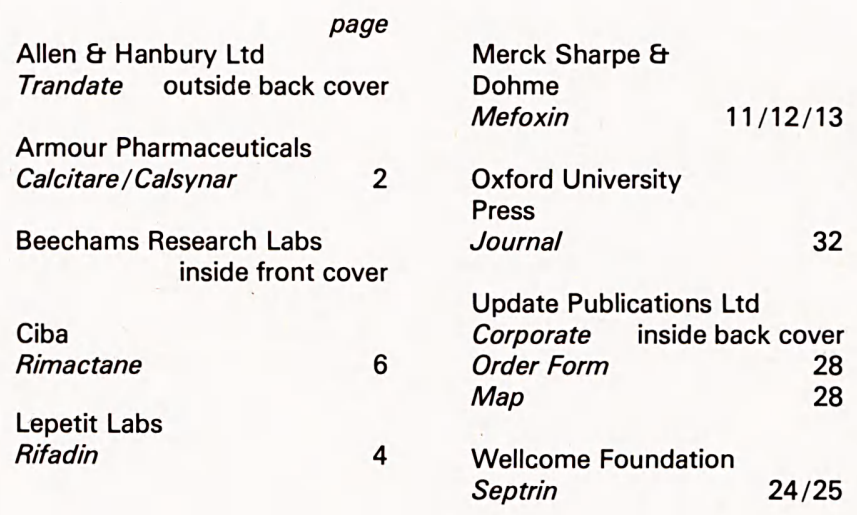

